\title{
Determining the Economic Manufacturing Lot Size with Expedited Fabrication Rate and Product Quality Assurance
}

\author{
Yuan-Shyi Peter Chiu \\ Department of Industrial Engineering \& Management, \\ Chaoyang University of Technology, Taichung, Taiwan. \\ E-mail: ypchiu@cyut.edu.tw \\ Yu-Ru Chen \\ Department of Industrial Engineering \& Management, \\ Chaoyang University of Technology, Taichung, Taiwan. \\ E-mail: a0981505188@gmail.com \\ Hua-Yao Wu \\ Department of Physics, College of Liberal Arts and Sciences, \\ State University of New York, Oswego, NY 13126, USA. \\ E-mail: huayao.wu@oswego.edu

\section{Chung-Li Chou} \\ Department of Business Administration, \\ Chaoyang University of Technology, Taichung, Taiwan. \\ Corresponding author: echungc@cyut.edu.tw
}

(Received July 24, 2019; Accepted November 14, 2019)

\begin{abstract}
Operations in manufacturing environments are turbulent. Thus, production managers must be capable of dealing with diverse and unexpected situations, such as either random production of imperfect items or unanticipated changes in customers' orders. Therefore, a decision-support-type of model is required to facilitate production managers in achieving their goals. We propose a precise model that can determine the economic lot size (ELS) by incorporating issues related to expedited fabrication rate and product quality-assurance during production. Thereby, fabrication rate can be adjusted with an extra setup and the consequent unit costs. In each fabrication cycle, random non-conforming products would be screened and identified. Such items would either be disposed of or reworked with consequent extra cost, to obtain a quality-assured final product. The ELS is determined with the aid of mathematical analyses and optimization processes. A numerical example is presented to demonstrate the applicability of our model and to depict diverse critical system characteristics that support managerial decision-making.
\end{abstract}

Keywords- Industrial engineering, Economic manufacturing lot size, Expeditious fabrication rate, Product quality assurance, Optimization

\section{Introduction}

Production managers, working in turbulent manufacturing environments, have to be capable of handling different unpredicted incidents, such as random imperfect quality items produced, or unanticipated changes in customers' orders, or unforeseen capacity amended due to reliability issues. To address these realities, we include expedited manufacturing rate and quality assurance issues in economic lot-sizing problem and plan to reveal and provide critical system information to support their decision makings. 
International Journal of Mathematical, Engineering and Management Sciences

Vol. 5, No. 2, 193-207, 2020

https://doi.org/10.33889/IJMEMS.2020.5.2.016

Expedited fabrication rate can be implemented, for example, via the built-in advance function from production equipment or through adding extra hours in a daily shift. It is an effective strategy to increase short-term capacity, and therefore, reduce uptime to help smooth production scheduling. Unsurprisingly, it has drawn broad attention from researchers in past decades. Wolisz (1984) explored the optimal manufacturing rate for a two-stage queuing system with finite transitional storage and having a single server in each stage. Formulations of system optimization criteria were accomplished and applied to the existing models in the literature. As a result, the maximal manufacturing rate for the case of exponential service time was gained in closed form. Numerical results illustrated variations in the specific coefficient of system parameters' effects on the proposed system as compared to the actual results from the literature. Khouja and Mehrez (1994) examined an economic production lot-size problem, where the fabrication rate was treated as a decision variable, and unit production cost was a function of the manufacturing rate. In addition, defective rate of the process increases as fabrication rate goes up. They solved the problem with specific functions of unit cost and defective rate, and used a numerical example to illustrate their obtained results and discussed on the tradeoff between functions of product quality and unit cost increase as fabrication rate altered. Ouyang et al. (2005) studied a vendor-buyer integrated inventory problem with price-sensitive demand rate, adjustable fabrication rate, and under trade credit situation. Their objective was to maximize profit of the system. An algorithm was presented to simultaneously decide the optimal retail price, buyer's ordering quantity, and shipments per production run for such a vendor-buyer integrated problem. Their result showed that applying trade-credit strategy could be a win-win situation for both vendor and buyer; and also indicates that if the vendor's fabrication rate is close to product demand rate, the profit notably increases. Njike et al. (2012) explored the interactions between defective items and optimal control over fabrication rate, lead time, and stock in a manufacturing system. Their objective was to minimize the expected system costs consisting of maintenance, stock holding, and backordering. They considered two maintenance states of realtime manufacturing system which controlled by two key factors, namely fabrication and maintenance rates. Through observing $\mathrm{N}$ operational states of the system under the condition-based maintenance discipline and using the dynamic programming, they showed that finding the optimal policy becoming a piecewise deterministic optimal control problem. Finally, they provided a numerical illustration and conducted a sensitivity analysis using a set of data from real manufacturing system. Neidigh and Harrison (2013) proposed the heuristic and linear approximation approaches to seek the near optimal lot-size solutions for a real manufacturing firm located in PA, wherein learning effects in a nonlinear manufacturing process were considered. The average fabrication time of a part varies based on different lot sizes, and fabrication time declines as the lot size increases due to learning effect. The authors employed the discrete time periods to represent the fabrication lots so that the optimal production schedule that minimizes fabrication and holding costs can be derived. The author started with applying their approach to the single-product problem, then expanding it to the multiple product cases. From numerous sets of multi-period tests, the authors demonstrated that their approach was capable of offering feasible fabrication schedule with total costs close to that of the optimal model. Extra studies addressed diverse aspects of manufacturing systems with variable/flexible fabrication rate can be referred to elsewhere (Giri and Dohi, 2005; Glock, 2010; Sajadieh and Larsen, 2015; Bottani et al., 2017; Liu et al., 2017; Ahranjani and Matin, 2018; Ameen et al., 2018; Chiu et al., 2018a,b,c).

In contrast to the assumption of perfect stock quality as in classic economic fabrication lot-size problem (Taft, 1918), in real manufacturing environments, random nonconforming products are often produced owing to diverse unanticipated factors. Shih (1980) studied optimal inventory policies with shortage situations caused by defective items. It was assumed that in the accepted lot, 
International Journal of Mathematical, Engineering and Management Sciences

Vol. 5, No. 2, 193-207, 2020

https://doi.org/10.33889/IJMEMS.2020.5.2.016

the percentage of random defective items follows a known probability distribution. The mathematical analysis helped derive the optimal solutions to the studied problem, and the results were compared to that in traditional models using numerical examples. Boone et al. (2000) investigated the influence of imperfect processes on cycle length. Accordingly, a model was built and analyzed to offer production management guidelines on deciding correct fabrication run times for dealing with defective products and machine breakdown occurrences. Pillai and Chandrasekharan (2008) studied the fabrication system considering rework and scrap products. The Markovian process was employed to simulate the material flow, and the processes for rework and scrap items were considered as the absorbing Markov states. The authors applied their Markovian model to compute the required amount of raw materials correctly. Cardós et al. (2013) proposed a heuristic intending to lower the inventory level for repairable parts used by a real airline company, under the service level constraints. The authors showed that their proposed method outperformed the current common sales replacement policy in terms of inventory/cost reduction. To reduce the overall manufacturing costs, sometimes, the nonconforming items are inspected and further categorized as scrap and repairable items, and with an extra repairing cost to assure the latter meeting the desired quality level. Roy et al. (2014) examined a stochastic demand economic fabrication lot-size problem with the exponentially distributed time to failure, wherein the defective stocks are accumulated during the unstable process, and they are reworked right away. Shortages are backordered, both complete and partial backlogging plans were analyzed. The authors built a profit maximization model to decide the optimal lot-size along with the production rate. Numerous examples were offered to show the applicability of their results. Additional papers that investigated different features of imperfect manufacturing systems can be found elsewhere (Wee et al., 2007; Khanna et al., 2017; Mošorinski et al., 2017; Chiu et al., 2018d; Pearce et al., 2018; Souha et al., 2018; Zhao et al., 2018; Saha et al., 2019; Taleizadeh et al., 2019).

The main contribution of this work is that a precise model is developed to enable the production managers to take advantage of this decision support type of tool to reveal the following characteristics of a fabrication system with expedited rate and quality assurance: (a) the optimal replenishment lot size and total system cost; (b) the effect of differences in nonconforming rate $x$ on cost components of the system; (c) the joint impacts of $x$ and total scrap rate $\varphi$ on total system cost; (d) the influence of fabrication rate increase on machine utilization and on manufacturing lot size; (e) variations of unit cost increase percentage effects on total system cost; and (f) changes of fabrication rate increase percentage effects on different system cost components. For a small number of studies that have investigated the aforementioned joint impact of expedited fabrication rate and product quality assurance issues on economic manufacturing lot size, this study aims to fill the gap.

\section{Problem Description and Modeling}

Consider a particular product with annual demand rate $\lambda$ needs to be satisfied by an EMQ-based fabrication-inventory system incorporating an expedited fabrication rate in order to shorten the production cycle time. Assuming that fabrication rate per unit time can be speeded up through the existing advance function from the machine, or via the extension of daily running time (such as switching from an eight-hour shift to two or three shifts per day, or even by adding a portion of time (e.g., a few overtime hours per day)). Consequently, the following increasing production setup $\operatorname{cost} K_{\mathrm{A}}$ and unit manufacturing $\operatorname{cost} C_{\mathrm{A}}$ are associated with this nonstandard production rate $P_{\mathrm{A}}$ :

$$
\begin{aligned}
& K_{\mathrm{A}}=\left(1+\alpha_{2}\right) K \\
& C_{\mathrm{A}}=\left(1+\alpha_{3}\right) C
\end{aligned}
$$


International Journal of Mathematical, Engineering and Management Sciences

Vol. 5, No. 2, 193-207, 2020

https://doi.org/10.33889/IJMEMS.2020.5.2.016

$$
P_{\mathrm{A}}=\left(1+\alpha_{1}\right) P
$$

where $K, C, P$, and $\alpha_{\mathrm{i}}$ denote regular production setup cost, unit manufacturing cost, the standard manufacturing rate per year, and the linking factors between these adjustable and regular variables, respectively. For example, $\alpha_{1}=0.5$ represents the adjusted production rate is $50 \%$ higher than the standard one, and $\alpha_{3}=0.2$ means that unit fabrication cost is $120 \%$ of the regular unit cost.

It is also assumed that during the fabrication process, $x$ percentage of the produced items are nonconforming, and its fabrication rate is $d_{\mathrm{A}}$ (hence, $d_{\mathrm{A}}=P_{\mathrm{A}} x$ ). Shortages are not permitted in this study. Hence, $P_{\mathrm{A}}>\left(\lambda+d_{\mathrm{A}}\right)$, or $P_{\mathrm{A}}-d_{\mathrm{A}}-\lambda>0$ (see Figure 1).

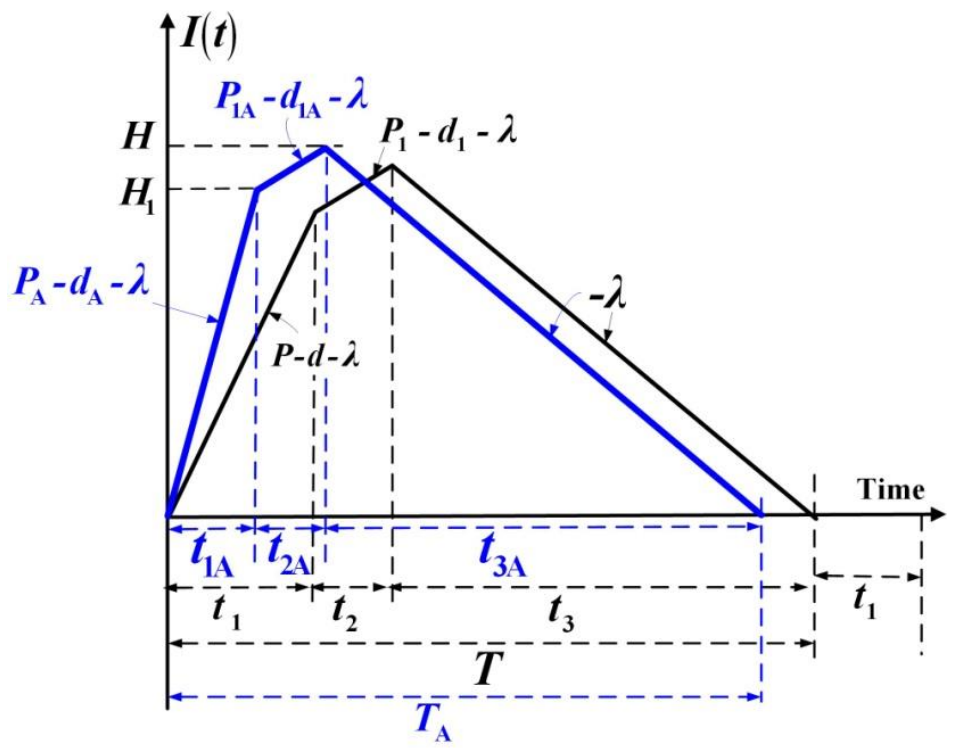

Figure 1. Level of on-hand inventories in the proposed EMQ-based system incorporating an expeditious production rate (in blue) as compared to that in conventional EMQ system (in black)

All non-conforming items are examined and grouped as scrap items (i.e., a $\theta$ portion) and reworkable items (i.e., $(1-\theta)$ portion). In each production cycle, the rework process follows the regular fabrication, at a rate of $P_{1 \mathrm{~A}}$ (where $P_{1 \mathrm{~A}}=\left(1+\alpha_{1}\right) P_{1}$, and $P_{1}$ denotes standard rework rate). On-hand defective inventory status is depicted in Figure 2. 
International Journal of Mathematical, Engineering and Management Sciences

Vol. 5, No. 2, 193-207, 2020

https://doi.org/10.33889/IJMEMS.2020.5.2.016

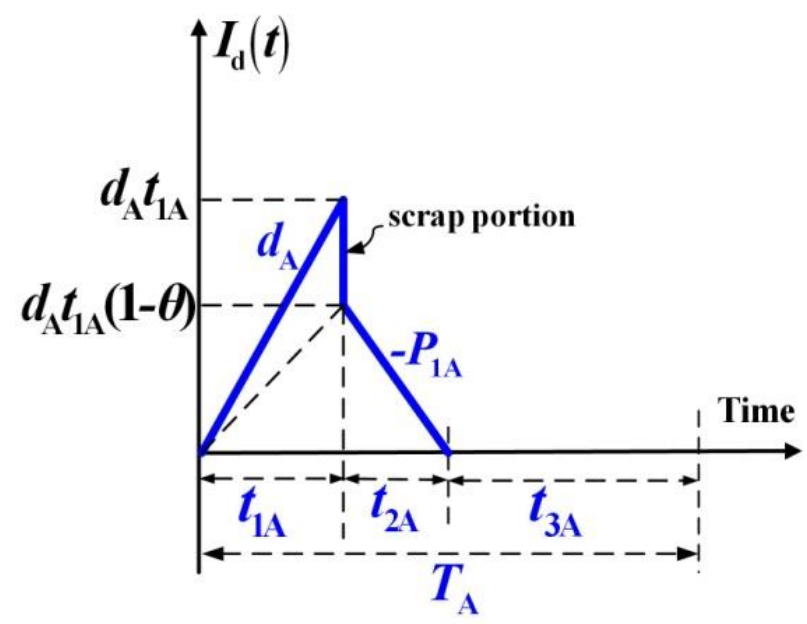

Figure 2. Status of on-hand imperfect items in the proposed system

During rework, a $\theta_{1}$ portion fails and is scrapped. The on-hand level of scraps produced during the fabrication and rework times are shown in Figure 3.

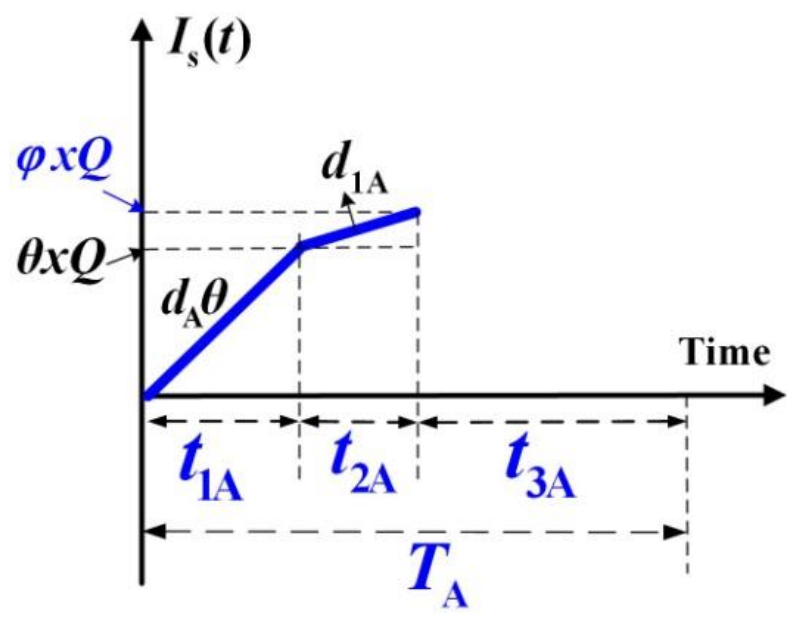

Figure 3. Status of scraps in the proposed system

Other parameters used in the proposed EMQ-based incorporating an adjustable manufacturing rate include the following:

$Q=$ replenishment lot-size per cycle - the decision variable,

$H_{1}=$ level of on-hand inventories when the fabrication uptime ends,

$H=$ level of on-hand inventories when rework ends,

$t_{1 \mathrm{~A}}=$ fabrication uptime,

$t_{2 \mathrm{~A}}=$ the rework time, 
International Journal of Mathematical, Engineering and Management Sciences

Vol. 5, No. 2, 193-207, 2020

https://doi.org/10.33889/IJMEMS.2020.5.2.016

$t_{3 \mathrm{~A}}=$ production downtime,

$T_{\mathrm{A}}=$ cycle time,

$C_{\mathrm{R}}=$ unit reworking cost,

$C_{\mathrm{S}}=$ unit disposal cost,

$h=$ unit holding cost,

$d_{1 \mathrm{~A}}=$ fabrication rate of scrap items in rework process,

$h_{1}=$ holding cost per reworked item,

$\varphi=$ total scrap rate of defective items, where $\varphi=\left[\theta+(1-\theta) \theta_{1}\right]$,

$I(t)=$ on-hand stock level at time $t$,

$I_{\mathrm{d}}(t)=$ on-hand defective stock level at time $t$,

$I_{\mathrm{S}}(t)=$ on-hand scrap stock level at time $t$,

$t_{1}=$ fabrication uptime in conventional EMQ system,

$t_{2}=$ rework time in a conventional EMQ system,

$t_{3}=$ depletion time in a conventional EMQ system,

$T=$ cycle time in a conventional EMQ system,

$D=$ production rate of nonconforming stocks in a conventional EMQ system,

$d_{1}=$ production rate of scrap items during the rework of a conventional EMQ system,

$T C(Q)=$ total fabrication-inventory cost per cycle,

$\mathrm{E}\left[T_{\mathrm{A}}\right]=$ the expected cycle time,

$\mathrm{E}[T C U(Q)]=$ the annual expected total fabrication-inventory cost.

\subsection{Formulations}

According to the problem description (see Figures 1-3), we observe the following equations:

$$
\begin{aligned}
& t_{1 \mathrm{~A}}=\frac{Q}{P_{\mathrm{A}}}=\frac{H_{1}}{P_{\mathrm{A}}-d_{\mathrm{A}}-\lambda} \\
& t_{2 \mathrm{~A}}=\frac{x Q(1-\theta)}{P_{1 \mathrm{~A}}} \\
& t_{3 \mathrm{~A}}=\frac{H}{\lambda} \\
& T_{A}=t_{1 A}+t_{2 A}+t_{3 A}=\frac{Q(1-\varphi x)}{\lambda} \\
& H_{1}=\left(P_{A}-d_{A}-\lambda\right) t_{1 A}=\left[\left(1+\alpha_{1}\right) P-d_{A}-\lambda\right] t_{1 A} \\
& H=H_{1}+\left(P_{1 A}-d_{1 A}-\lambda\right) t_{2 A} \\
& P_{1 A}=\left(1+\alpha_{1}\right) P_{1}
\end{aligned}
$$

Maximal on-hand imperfect inventories during $t_{1 \mathrm{~A}}$ are

$$
d_{A} t_{1 A}=x P_{A} t_{1 A}=x Q
$$

Also, total scrap items fabricated in $t_{1 \mathrm{~A}}$ and $t_{2 \mathrm{~A}}$ are

$$
\theta(x Q)+\theta_{1}[(1-\theta) x Q]=\left[\theta+(1-\theta) \theta_{1}\right] x Q=\varphi x Q
$$


International Journal of Mathematical, Engineering and Management Sciences

Vol. 5, No. 2, 193-207, 2020

https://doi.org/10.33889/IJMEMS.2020.5.2.016

$T C(Q)$ includes the setup and variable fabrication costs, the reworking and disposal costs, and stock holding costs for perfect quality, reworking, and nonconforming stocks in a cycle. So, $T C(Q)$ is

$$
\begin{aligned}
T C(Q)=K_{A}+ & C_{A} Q+C_{R}[x Q(1-\theta)]+C_{S}(\varphi x Q)+h_{1} \frac{P_{1 A} t_{2 A}}{2}\left(t_{2 A}\right) \\
+ & h\left[\frac{\left(x P_{A}\right) t_{1 A}+H_{1}}{2}\left(t_{1 A}\right)+\frac{H+H_{1}}{2}\left(t_{2 A}\right)+\frac{H}{2}\left(t_{3 A}\right)\right]
\end{aligned}
$$

Substitute $K_{\mathrm{A}}, C_{\mathrm{A}}, P_{\mathrm{A}}$, and $P_{1 \mathrm{~A}}$ (i.e., Eqs. (1)-(3) and (10)) in Eq. (13)), $T C(Q)$ becomes

$$
\begin{aligned}
& T C(Q)=\left[\left(1+\alpha_{2}\right) K\right]+\left[\left(1+\alpha_{3}\right) C\right] Q+C_{R}[x Q(1-\theta)]+C_{S}(\varphi x Q) \\
& +h_{1} \frac{\left(1+\alpha_{1}\right) P_{1} t_{2 A}}{2}\left(t_{2 A}\right)+h\left\{\frac{H_{1}+x\left[\left(1+\alpha_{1}\right) P\right] t_{1 A}}{2}\left(t_{1 A}\right)+\frac{H_{1}+H}{2}\left(t_{2 A}\right)+\frac{H}{2}\left(t_{3 A}\right)\right\}
\end{aligned}
$$

Apply the expected values of $x$ to cope with the randomness of nonconforming rate in the fabrication process and substitute all parameters from Eqs. (4) to (12) in Eq. (14), and E[TCU(Q)] can be derived as follows:

$$
\begin{aligned}
E[T C U(Q)]= & \frac{E[T C(Q)]}{E\left[T_{A}\right]} \\
= & \lambda\left\{\left[\left(1+\alpha_{3}\right) C\right] E_{0}+C_{R}(1-\theta) E_{1}+C_{S} \varphi E_{1}\right\}+\frac{\left[\left(1+\alpha_{2}\right) K\right] \lambda}{Q} E_{0} \\
& +\frac{h Q(1-\varphi E[x])}{2}-\frac{h \lambda Q(1-2 \varphi E[x])}{2\left(1+\alpha_{1}\right) P} E_{0} \\
& +\frac{\lambda Q(1-\theta)\left[h_{1}(1-\theta)-h\right]}{2\left(1+\alpha_{1}\right) P_{1}} E_{2}+\frac{h \lambda Q \varphi(1-\theta)}{2\left(1+\alpha_{1}\right) P_{1}} E_{2}
\end{aligned}
$$

where

$$
E_{0}=\frac{1}{1-\varphi E[x]} ; \quad E_{1}=\frac{E[x]}{1-\varphi E[x]} ; \quad E_{2}=\frac{E[x]^{2}}{1-\varphi E[x]}
$$

\section{Optimal Manufacturing Lot Size}

To determine the optimal lot-size, we need first to prove that $\mathrm{E}[T C U(Q)]$ is convex. Calculate the first- and second-derivatives of $E[T C U(Q)]$ concerning $Q$, we obtain

$$
\begin{aligned}
\frac{d E[T C U(Q)]}{d Q}= & -\frac{\left[\left(1+\alpha_{2}\right) K\right] \lambda}{Q^{2}} E_{0}+\frac{h(1-\varphi E[x])}{2}-\frac{h \lambda(1-2 \varphi E[x])}{2\left(1+\alpha_{1}\right) P} E_{0} \\
& +\frac{\lambda(1-\theta)\left[h_{1}(1-\theta)-h\right]}{2\left(1+\alpha_{1}\right) P_{1}} E_{2}+\frac{h \lambda \varphi(1-\theta)}{2\left(1+\alpha_{1}\right) P_{1}} E_{2}
\end{aligned}
$$




$$
\frac{d^{2} E[\operatorname{TCU}(Q)]}{d Q^{2}}=\frac{2\left[\left(1+\alpha_{2}\right) K\right] \lambda}{Q^{3}} E_{0}
$$

Because $K, \alpha_{2}, Q, E_{0}$, and $\lambda$ are all positive, Eq. (18) results positive. So, $E[T C U(Q)]$ is strictly convex for $Q$ different from zero. Set the first derivative of $E[T C U(Q)]$ equal to zero; one can solve the optimal $Q^{*}$ as follows:

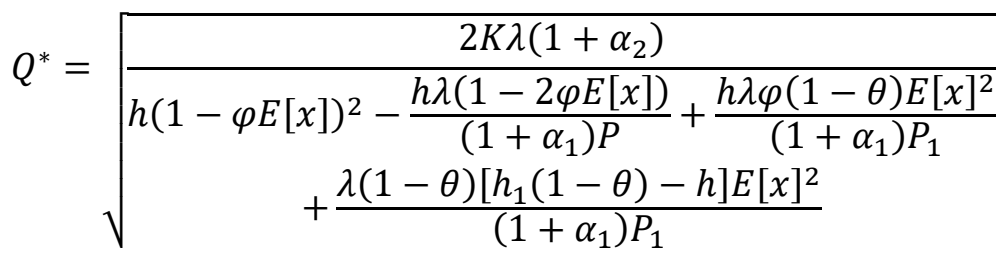

\section{Numerical Example with Discussion}

Applicability of the obtained result along with sensitivity analyses is demonstrated through a numerical example using the following parameter values:

$$
\begin{array}{ll}
\lambda & =4,000 \\
K & =\$ 5,000 \\
h & =\$ 30 \\
C & =\$ 100 \\
x & =\text { uniformly distributed variable within the interval of }[0,0.2] \\
P & =20,000 \\
\alpha_{1} & =0.5 \\
\alpha_{2} & =0.1\left(\text { assume } \alpha_{2}=0.2\left(\alpha_{1}\right)\right) \\
\alpha_{3} & =0.25\left(\text { assume } \alpha_{3}=0.5\left(\alpha_{1}\right)\right) \\
P_{\mathrm{A}} & =30,000 \\
K_{\mathrm{A}} & =\$ 5,500 \\
C_{\mathrm{A}} & =\$ 125, \\
h_{1} & =\$ 40 \\
C_{\mathrm{R}} & =\$ 60 \\
\theta & =0.1, \\
\theta_{1} & =0.1 \\
\varphi & =0.19\left(\text { since } \varphi=\left[\theta+(1-\theta) \theta_{1}\right]\right) \\
C_{\mathrm{S}} & =\$ 20 .
\end{array}
$$

First, by applying equation (19), the economic manufacturing lot size $Q^{*}=1325$ can be found. Then, by calculating equation (15), $E\left[T C U\left(Q^{*}\right)\right]=\$ 567,114$ is obtained. The result of the sensitivity analysis of decision variable $Q$ effects on the expected cost function $E[T C U(Q)]$ as displayed in Figure 4. 
International Journal of Mathematical, Engineering and Management Sciences

Vol. 5, No. 2, 193-207, 2020

https://doi.org/10.33889/IJMEMS.2020.5.2.016

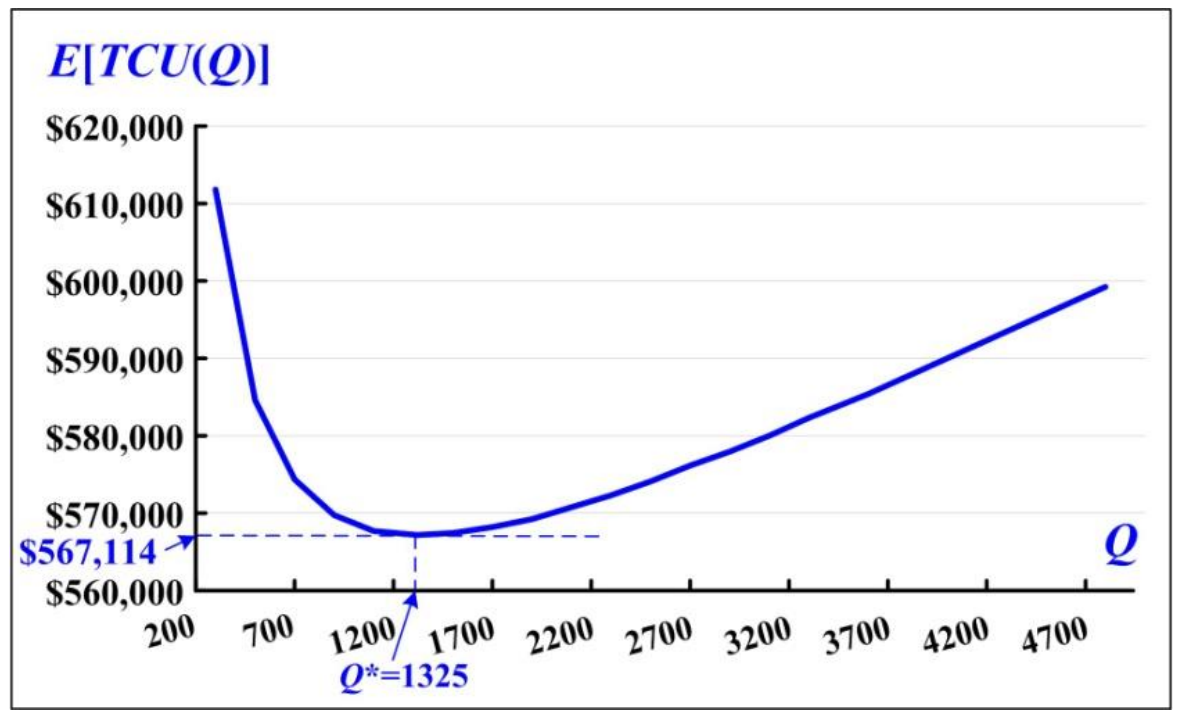

Figure 4. The result of the sensitivity analysis of decision variable $Q$ effects on $E[T C U(Q)]$

Figure 5 illustrates variations in $x$ effects on different cost components. It specifies that as $x$ goes up, all cost components concerning product quality assurances (including scrap, reworking, and variable fabrication costs) increases significantly. Further analytical results of the joint influences of $x$ and $\varphi$ on $E[T C U(Q)]$ is exhibited in Figure 6. Unsurprisingly, as $x$ rises, $E[T C U(Q)]$ goes up accordingly; and as $\varphi$ rises, $E[T C U(Q)]$ increases notably.

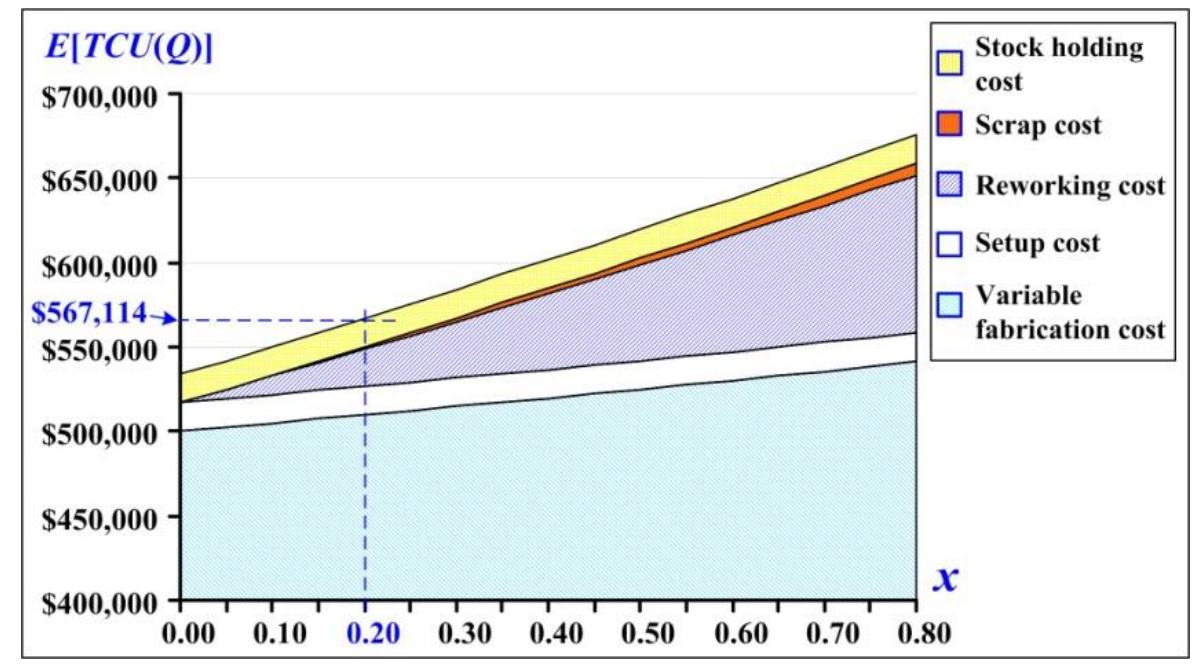

Figure 5. Variations of nonconforming rate x effects on different system's cost components 
International Journal of Mathematical, Engineering and Management Sciences

Vol. 5, No. 2, 193-207, 2020

https://doi.org/10.33889/IJMEMS.2020.5.2.016

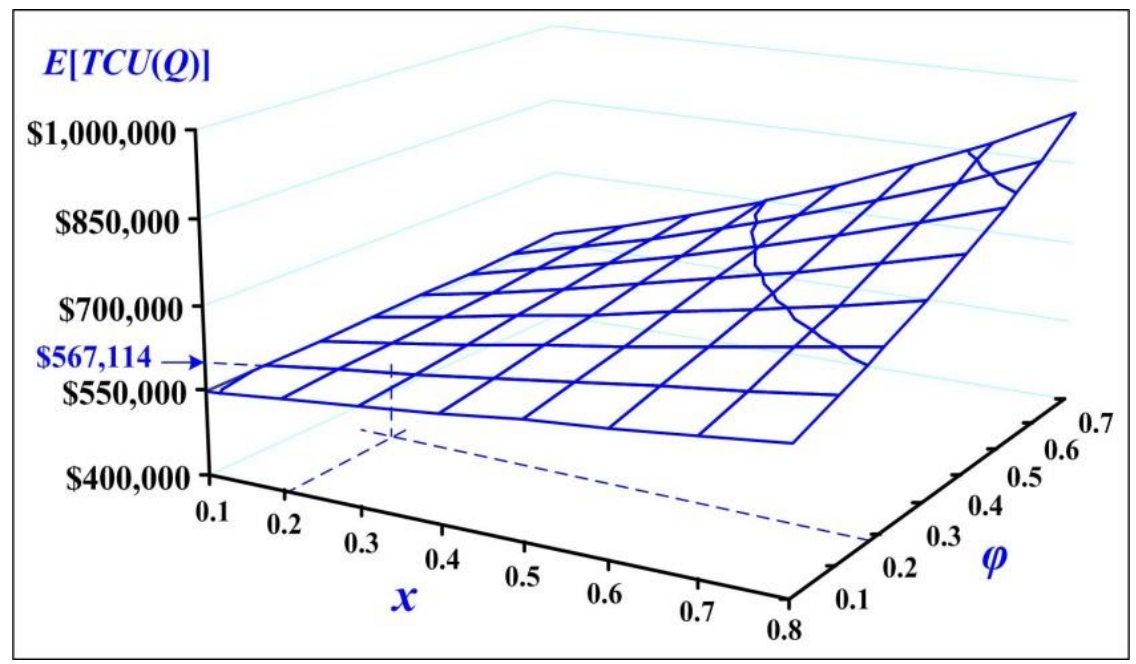

Figure 6. Joint effects of nonconforming rate $x$ and overall scrap rate $\varphi$ on $E[T C U(Q)]$

The expedited rate effects on the proposed system are further investigated, and various critical managerial decisions related information on fabrication times and machine utilization are revealed (see Table 1). The obtained analytical results in Table 1, can provide production managers with the impact of the rate increase percentage on uptime, reworking time, cycle time, utilization, and utilization decrease percentage.

Table 1. Variations of fabrication rate increase percentage $\left(\alpha_{1}\right)$ effects on uptime, rework time, cycle time, utilization, and utilization decrease percentage

\begin{tabular}{cccccc}
\hline $\begin{array}{c}\alpha_{1} \\
\%\end{array}$ & $\begin{array}{c}\text { Uptime } \\
\left(t_{1 \mathrm{~A}}\right)\end{array}$ & $\begin{array}{c}\text { Rework time } \\
\left(t_{2 \mathrm{~A}}\right)\end{array}$ & $E\left[T_{\mathrm{A}}\right]$ & $\begin{array}{c}\text { Utilization } \\
\left\{\left(t_{1 \mathrm{~A}}+t_{2 \mathrm{~A}}\right) / E\left[T_{\mathrm{A}}\right]\right\}\end{array}$ & $\begin{array}{c}\text { Utilization } \\
\text { decreases } \\
\text { percentage }\end{array}$ \\
\hline $0 \%$ & 0.0657 & 0.0236 & 0.3221 & $27.73 \%$ & - \\
$10 \%$ & 0.0596 & 0.0215 & 0.3218 & $25.21 \%$ & $-9.09 \%$ \\
$20 \%$ & 0.0547 & 0.0197 & 0.3220 & $23.11 \%$ & $-16.67 \%$ \\
$30 \%$ & 0.0506 & 0.0182 & 0.3227 & $21.33 \%$ & $-23.08 \%$ \\
$40 \%$ & 0.0471 & 0.0170 & 0.3236 & $19.80 \%$ & $-28.57 \%$ \\
$50 \%$ & 0.0442 & 0.0159 & 0.3248 & $18.48 \%$ & $-33.33 \%$ \\
\hline $60 \%$ & 0.0416 & 0.0150 & 0.3263 & $17.33 \%$ & $-37.50 \%$ \\
$70 \%$ & 0.0393 & 0.0142 & 0.3278 & $16.31 \%$ & $-41.18 \%$ \\
$80 \%$ & 0.0373 & 0.0134 & 0.3295 & $15.40 \%$ & $-44.44 \%$ \\
$90 \%$ & 0.0355 & 0.0128 & 0.3312 & $14.59 \%$ & $-47.37 \%$ \\
$100 \%$ & 0.0340 & 0.0122 & 0.3331 & $13.86 \%$ & $-50.00 \%$ \\
\hline $110 \%$ & 0.0325 & 0.0117 & 0.3350 & $13.20 \%$ & $-52.38 \%$ \\
$120 \%$ & 0.0312 & 0.0112 & 0.3369 & $12.60 \%$ & $-54.55 \%$ \\
$130 \%$ & 0.0300 & 0.0108 & 0.3389 & $12.06 \%$ & $-56.52 \%$ \\
$140 \%$ & 0.0290 & 0.0104 & 0.3409 & $11.55 \%$ & $-58.33 \%$ \\
$150 \%$ & 0.0280 & 0.0101 & 0.3429 & $11.09 \%$ & $-60.00 \%$ \\
\hline $160 \%$ & 0.0271 & 0.0097 & 0.3450 & $10.66 \%$ & $-61.54 \%$ \\
$170 \%$ & 0.0262 & 0.0094 & 0.3471 & $10.27 \%$ & $-62.96 \%$ \\
$180 \%$ & 0.0254 & 0.0092 & 0.3492 & $9.90 \%$ & $-64.29 \%$ \\
$190 \%$ & 0.0247 & 0.0089 & 0.3513 & $9.56 \%$ & $-65.52 \%$ \\
$200 \%$ & 0.0240 & 0.0086 & 0.3534 & $9.24 \%$ & $-66.67 \%$ \\
\hline
\end{tabular}


International Journal of Mathematical, Engineering and Management Sciences

Vol. 5, No. 2, 193-207, 2020

https://doi.org/10.33889/IJMEMS.2020.5.2.016

From Table 1, diverse critical in-depth system information can be exposed. For instance, changes in fabrication rate increase percentage $\left(\alpha_{1}\right)$ effects on machine utilization become available for supporting managerial decision makings (see Figure 7). It is noted that as assumed by our example, when fabrication expeditious rate $\alpha_{1}=0.5$, machine utilization ratio drops to $18.48 \%$ (from $27.73 \%$, and that is a decrease of $33.33 \%$ ); and as $\alpha_{1}$ increases, utilization decreases significantly.

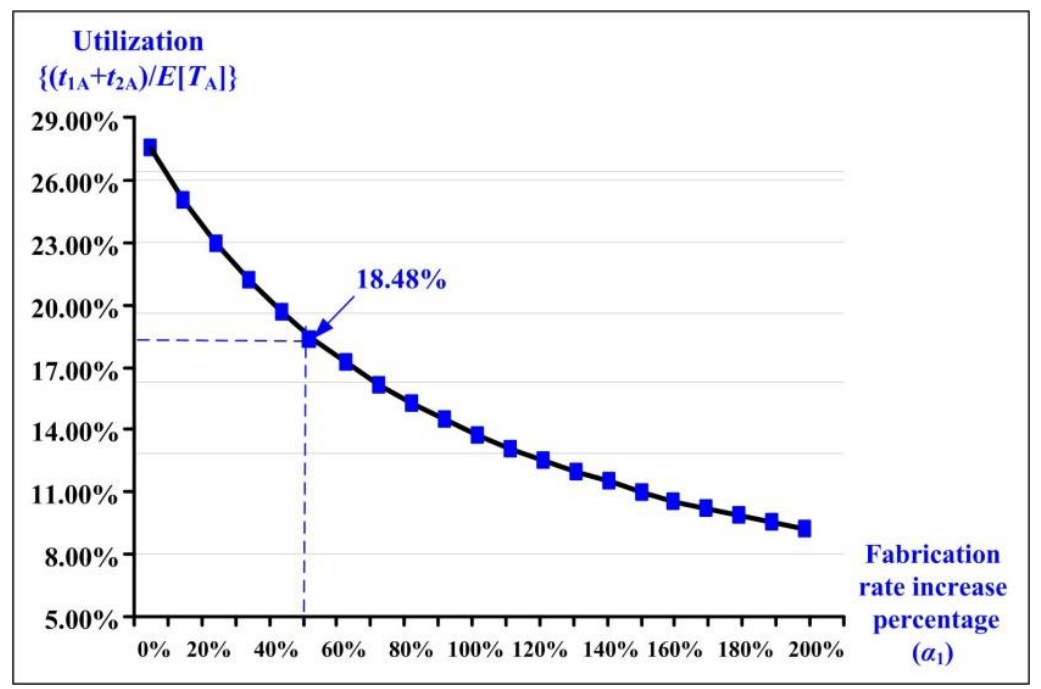

Figure 7. Fabrication rate increase percentage effects on the machine utilization

In addition to $\alpha_{1}$ effects on different fabrication times and utilization, joint influences of $\alpha_{1}$ and $\alpha_{3}$ on optimal lot-size $Q^{*}, E[T C U(Q)]$, and $E[T C U(Q)]$ increase percentage are also investigated to facilitate various critical in-depth system information for managerial decision makings. For example, fabrication rate increase percentage effects on the optimal manufacturing lot-size, as illustrated in Figure 8. It is noted that as assumed by our numerical example where $\alpha_{1}=0.5, Q^{*}=$ 1325 , and as $\alpha_{1}$ increases, optimal lot-size rises accordingly.

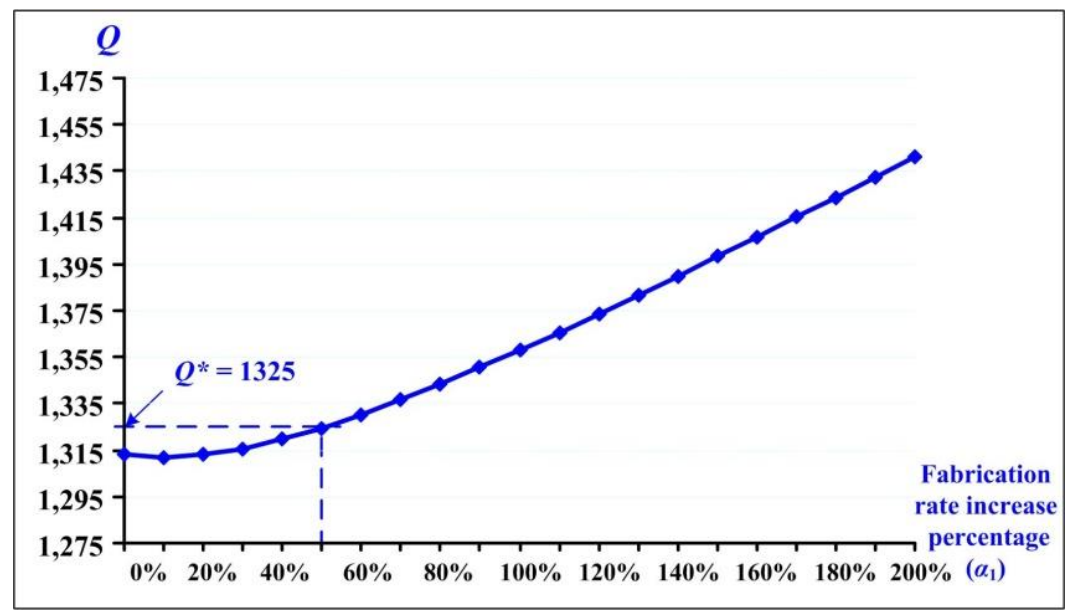

Figure 8. Differences in fabrication rate increase percentage effects on manufacturing lot-size 
International Journal of Mathematical, Engineering and Management Sciences

Vol. 5, No. 2, 193-207, 2020

https://doi.org/10.33889/IJMEMS.2020.5.2.016

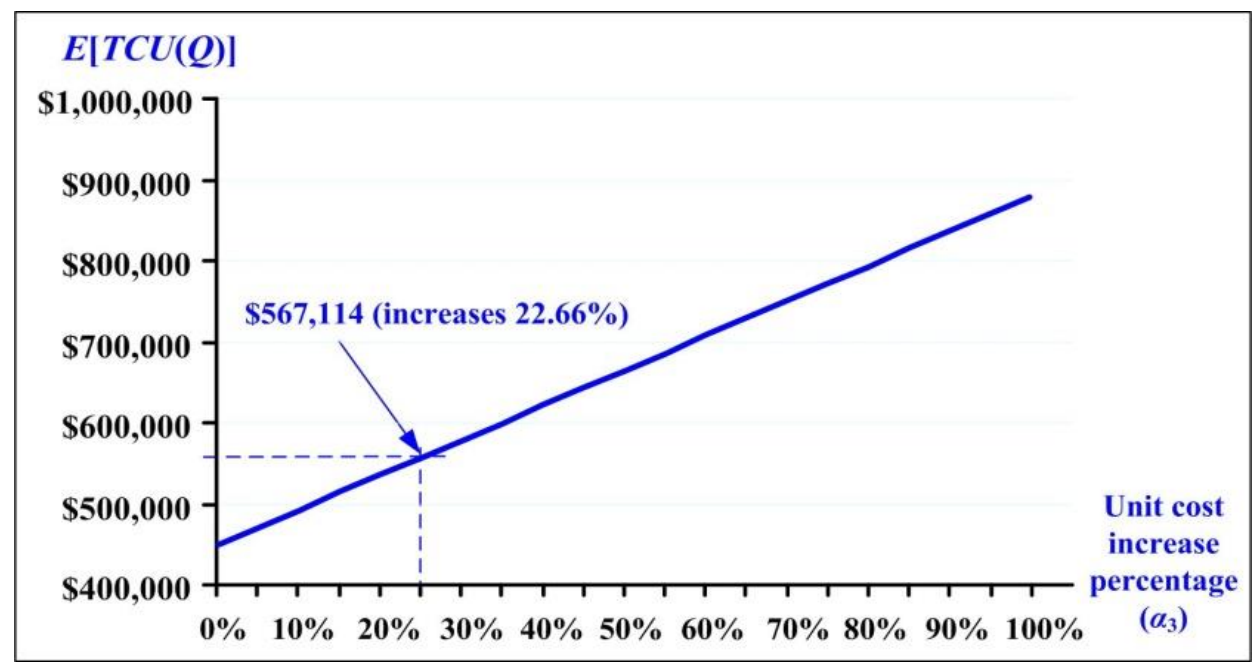

Figure 9. Variations of unit cost increase percentage effects on $E[T C U(Q)]$

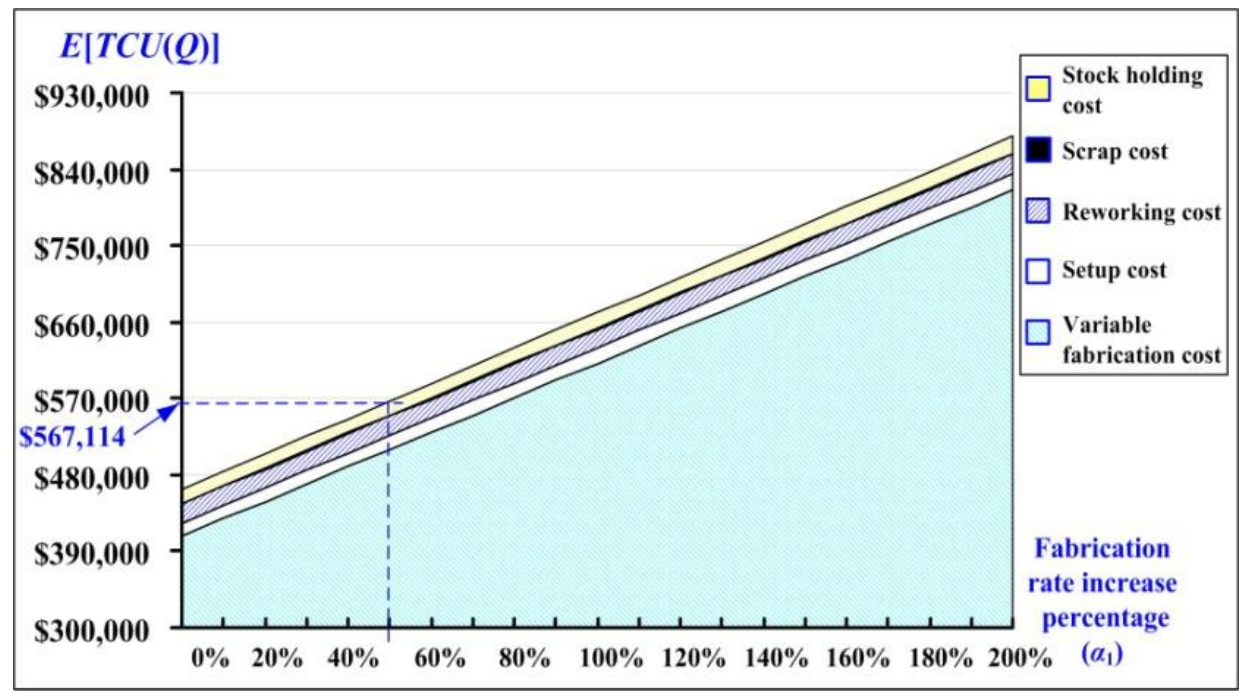

Figure 10. Changes of fabrication rate increase percentage effects on different cost components of $E[T C U(Q)]$

Analytical results also reveal the effect of variations in unit cost increase percentage on $E[T C U(Q)]$ (see Figure 9). It indicates that as assumed by our example at $\alpha_{3}=0.25$ (i.e., corresponding to $\alpha_{1}=$ 0.5 ), $E[T C U(Q)]=\$ 567,114$ (i.e., an increase of $22.66 \%$ from $\$ 462,357$ (where $\alpha_{1}=\alpha_{3}=0$ )); and as $\alpha_{3}$ increases, $E[T C U(Q)]$ goes up considerably. The further analysis exposes the effects of changes in fabrication rate increase percentage $\left(\alpha_{1}\right)$ on different cost components of $E[T C U(Q)]$, as displayed in Figure 10. These costs include stock holding, reworking, scrap, setup, and variable fabrication costs. It shows that as assumed by our example, at $\alpha_{1}=0.5, E[T C U(Q)]=\$ 567,114$. As $\alpha_{1}$ goes up, the variable fabrication cost increases drastically, but other cost components, such as stock holding, reworking, scrap, and setup costs insignificantly change. 
International Journal of Mathematical, Engineering and Management Sciences

Vol. 5, No. 2, 193-207, 2020

https://doi.org/10.33889/IJMEMS.2020.5.2.016

\subsection{Discussions and Limitation}

Upon accomplishment of the proposed study, production managers can take advantage of this decision support type of tool to reveal the following characteristics of a fabrication system with expedited rate and quality assurance: (i) the optimal lot size and total system cost; (ii) the effect of differences in nonconforming rate $x$ on cost components of the system; (iii) the joint influences of $x$ and total scrap rate $\varphi$ on total system cost; (iv) the impact of the rate increase on machine utilization and on manufacturing lot size; (v) variations of unit cost increase percentage effects on total system cost; and (vi) changes of fabrication rate increase percentage effects on different system cost components.

The limitations of the proposed model include: (1) the assumption of constant annual product demand rate, and (2) the assumption of the expedited fabrication rate can either through the existing advance function of the machine, or via the extension of daily running time (such as switching from an eight-hour shift to two or three shifts per day), hence, the latter overtime part of assumption (2) limits the expedited rate to $P_{\mathrm{A}} \leq 3 P$ or $\alpha_{1} \leq 2$.

\section{Conclusions}

A precise model is built in this study to help determine the economic lot-size for a fabricationinventory system with an expedited rate and product quality assurance. Mathematical analysis and optimization process are utilized in this study to derive the closed-form lot size solution. A numerical example is offered to depict the applicability of our result and reveal diverse critical system characteristics (refer to Table 1 and Figures 4 to 10) to facilitate production planning related decision makings. For future study, incorporating a probabilistic product demand rate and/or combining multiple/parallel machines into the proposed model will enhance the real-life applicability of the model.

\section{Conflict of Interest}

The authors confirm that there is no conflict of interest to declare for this publication.

\section{Acknowledgments}

Authors sincerely thank Ministry of Science and Technology of Taiwan for supporting this research under Grant No.: MOST 104-2410-H-324-008-MY2.

\section{References}

Ahranjani, L.Z., \& Matin, R.K. (2018). Technical measure of capacity utilization in two-stage production systems: a data envelopment analysis approach. Economic Computation and Economic Cybernetics Studies and Research, 52(2), 235-249.

Ameen, W., AlKahtani, M., Mohammed, M.K., Abdulhameed, O., \& El-Tamimi, A.M. (2018). Investigation of the effect of buffer storage capacity and repair rate on production line efficiency. Journal of King Saud University - Engineering Sciences, 30(3), 243-249.

Boone, T., Ganeshan, R., Guo, Y., \& Ord, J.K. (2000). The impact of imperfect processes on production run times. Decision Sciences, 31(4), 773-787. 
International Journal of Mathematical, Engineering and Management Sciences

Vol. 5, No. 2, 193-207, 2020

https://doi.org/10.33889/IJMEMS.2020.5.2.016

Bottani, E., Centobelli, P., Cerchione, R., Del Gaudio, L., \& Murino, T. (2017). Solving machine loading problem of flexible manufacturing systems using a modified discrete firefly algorithm. International Journal of Industrial Engineering Computations, 8(3), 363-372.

Cardós, M., Babiloni, E., Palmer Gato, M.E., \& Guijarro, E. (2013). A heuristic to minimize the inventory value of repairable parts with service constraints: application to an airline company. Journal of Industrial Engineering and Management, 6(3), 771-778.

Chiu, S.W., Lin, H-D., Chou, C-L., \& Chiu, Y-S.P. (2018a). Mathematical modeling for exploring the effects of overtime option, rework, and discontinuous inventory issuing policy on EMQ model. International Journal of Industrial Engineering Computations, 9(4), 479-490.

Chiu, S.W., Wu, H.Y., Chiu, Y-S.P., \& Hwang, M-H. (2018b). Exploration of finite production rate model with overtime and rework of nonconforming products. Journal of King Saud University - Engineering Sciences, 30(3), 224-231.

Chiu, Y-S.P., Chen, H-Y., Chiu, S.W., \& Chiu, V. (2018c). Optimization of an economic production quantitybased system with random scrap and adjustable production rate. Journal of Applied Engineering Science, 16(1), 11-18.

Chiu, Y-S.P., Chen, H-Y., Chiu, T., \& Chiu, S.W. (2018d). Incorporating flexible fabrication rate and random scrap into a FPR-based supply-chain system. Economic Computation and Economic Cybernetics Studies and Research, 52(2), 157-174.

Giri, B.C., \& Dohi, T. (2005). Computational aspects of an extended EMQ model with variable production rate. Computers and Operations Research, 32(12), 3143-3161.

Glock, C.H. (2010). Batch sizing with controllable production rates. International Journal of Production Research, 48(20), 5925-5942.

Khanna, A., Kishore, A., \& Jaggi, C.K. (2017). Inventory modeling for imperfect production process with inspection errors, Sales return, and imperfect rework process. International Journal of Mathematical, Engineering and Management Sciences, 2(4), 242-258.

Khouja, M., \& Mehrez, A. (1994). Economic production lot size model with variable production rate and imperfect quality. Journal of the Operational Research Society, 45(12), 1405-1417.

Liu, Y., Wu, H., Hou, J., Wei, C., \& Ren, W. (2017). An injection/production rate allocation method applied for polymer-surfactant flooding. Journal of Engineering Research, 5(2), 250-267.

Mošorinski, P., Prvulović, S., \& Palinkaš, I. (2017). Improving the characteristics of pneumatic transport of grain. Journal of Applied Engineering Science, 15(3), 218-224.

Neidigh, R.O., Harrison, T.P. (2013) Optimising lot sizing with nonlinear production rates in a multi-product single-machine environment. International Journal of Production Research, 51(12), 3561-3573.

Njike, A.N., Pellerin, R., \& Kenne, J.P. (2012). Simultaneous control of maintenance and production rates of a manufacturing system with defective products. Journal of Intelligent Manufacturing, 23(2), 323-332.

Ouyang, L-Y., Ho, C-H., \& Su, C-H. (2005). Optimal strategy for the integrated vendor-buyer inventory model with adjustable production rate and trade credit. International Journal of Information and Management Sciences, 16(4), 19-37.

Pearce, A., Pons, D., \& Neitzert, T. (2018) Implementing lean - outcomes from SME case studies. Operations Research Perspectives, 5, 94-104.

Pillai, V.M., \& Chandrasekharan, M.P. (2008). An absorbing Markov chain model for production systems with rework and scrapping. Computers and Industrial Engineering, 55(3), 695-706. 
International Journal of Mathematical, Engineering and Management Sciences

Vol. 5, No. 2, 193-207, 2020

https://doi.org/10.33889/IJMEMS.2020.5.2.016

Roy, M.D., Sana, S.S., \& Chaudhuri, K. (2014). An economic production lot size model for defective items with stochastic demand, backlogging and rework. IMA Journal of Management Mathematics, 25(2), $159-183$

Saha, S., Modak, N.M., Panda, S., \& Sana, S.S. (2019). Promotional coordination mechanisms with demand dependent on price and sales efforts. Journal of Industrial and Production Engineering, 36(1), 13-31.

Sajadieh, M.S., \& Larsen, C. (2015). A coordinated manufacturer-retailer model under stochastic demand and production rate. International Journal of Production Economics, 168, 64-70.

Shih, W. (1980). Optimal inventory policies when stock-outs result from defective products. International Journal of Production Research, 18(6), 677-686.

Souha, B., Soufien, G., \& Mtibaa, A. (2018). Using system generator to design a hardware implementation of a fault-tolerant control of induction motor for electrical vehicle. Journal of Engineering Research, $6(2), 138-154$.

Taft, E.W. (1918). The most economical production lot. Iron Age, 101(18), 1410-1412.

Taleizadeh, A.A., Yadegari, M., \& Sana, S.S. (2019). Production models of multiple products using a single machine under quality screening and reworking policies. Journal of Modelling in Management, 14(1), 232-259.

Wee, H.M., Yu, J., \& Chen, M.C. (2007). Optimal inventory model for items with imperfect quality and shortage back ordering. Omega, 35(1), 7-11.

Wolisz, A. (1984). Production rate optimization in a two-stage system with finite intermediate storage. European Journal Operational Research, 18(3), 369-376.

Zhao, X., Qian, C., Nakamura, S., \& Nakagawa, T. (2018). A summary of replacement policies with number of failures. International Journal of Mathematical, Engineering and Management Sciences, 3(2), 136150. 